\title{
REVIEW OF NASA'S PLANNED MARS PROGRAM
}

NATIONAL ACADEMY OF SCIENCES, WASHINGTON, DC

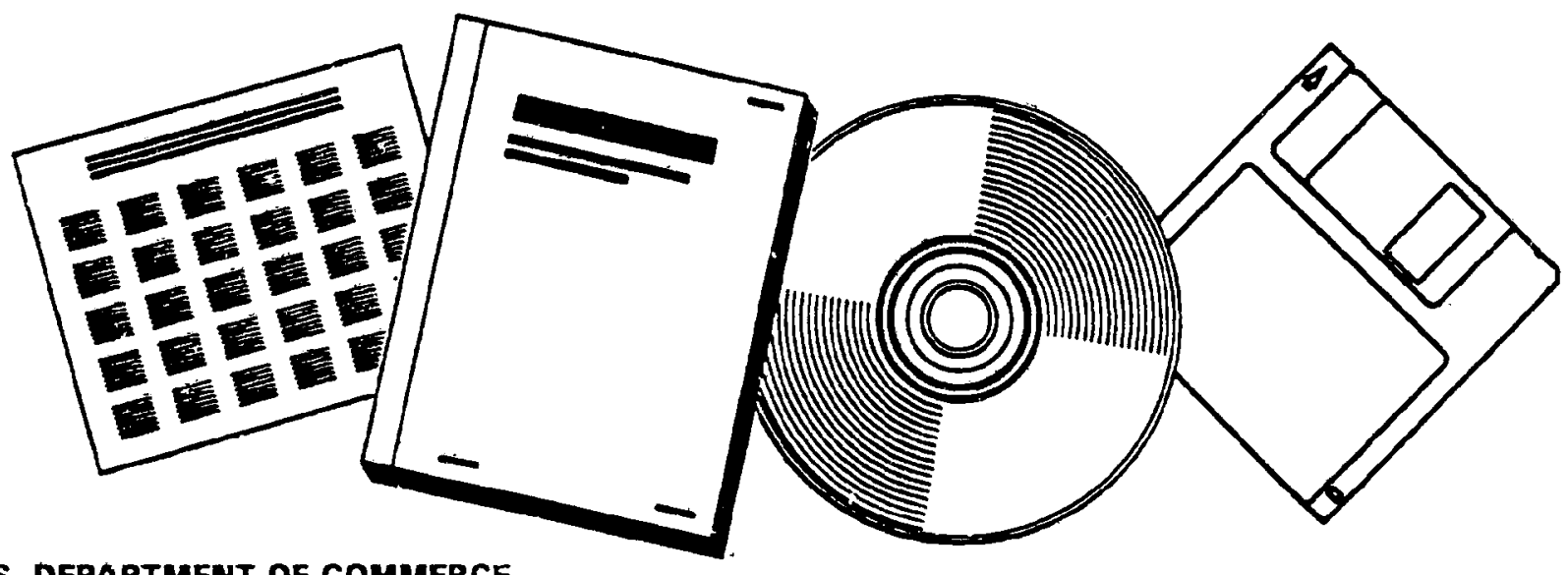

U.S. DEPARTMENT OF COMMERCE

National Technical Information Service 
Report Nos:

Title: Review of NASA's Planned Mars Program.

Date: 1996

Performing Organization: National Academy of Sciences. Washington. DC. Commission on Physical Sciences. Mathematics. and Applications.

Sponsoring Organization: *National Aeronautics and Space Administration. Washington. DC.

Contract NoS: NASA-NASW-4627

NTIS Field/Group Codes: 84B* (Extraterrestial Exploration). 84A (Astronautics). 84G UUnmanned Spacocraft)

Price: PC A04/MF A01

Availability: Available from the National Technical Information Service. Springfield. गA. 22161

Number of Pages: $36 p^{*}$

Keywords: *NASA space programs. *Mars exploration. *Project planning. *Goals. Mars(PTanet). Mars probes. Space missions. Mars pathfi:lder. Mars environment. Mission planning. Satellite-borne instruments. Spaceborne experiments, Data collection. Mars surveyor.

Abstract: Contents: Executive Summary: Introduction: Scientific Goals for the Exploration of Mars: Overview of Mars Surveyor and Jthers Mars Missions: Key Issues for NASA's Mars Exploration Program: and Assessment of the Scientific Potential of NASA's Mars Exploration Program. 


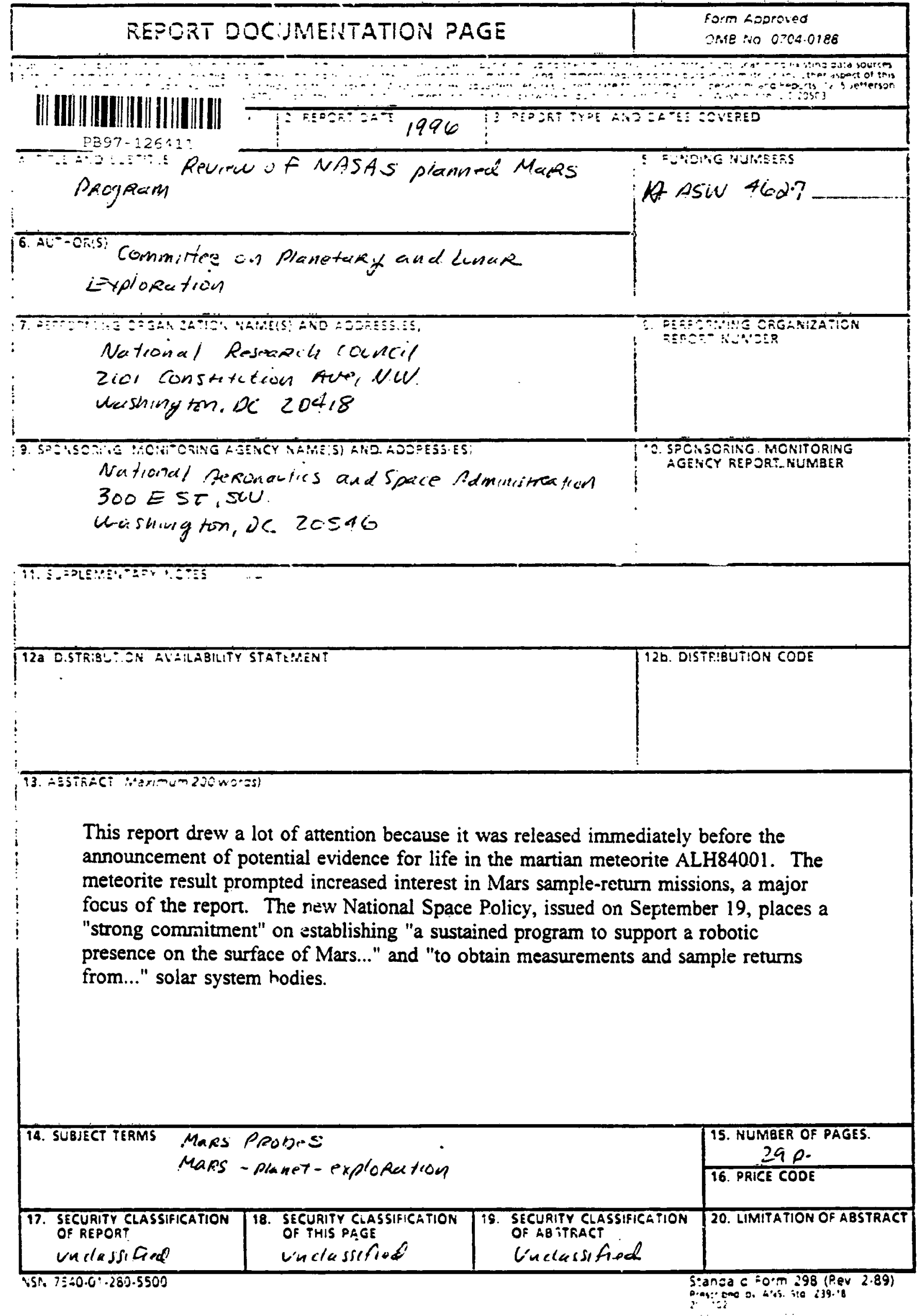




\section{|| |||||||||||||||||||||||||||||| \\ Review of NASA's Planned Mars}

\section{Program}

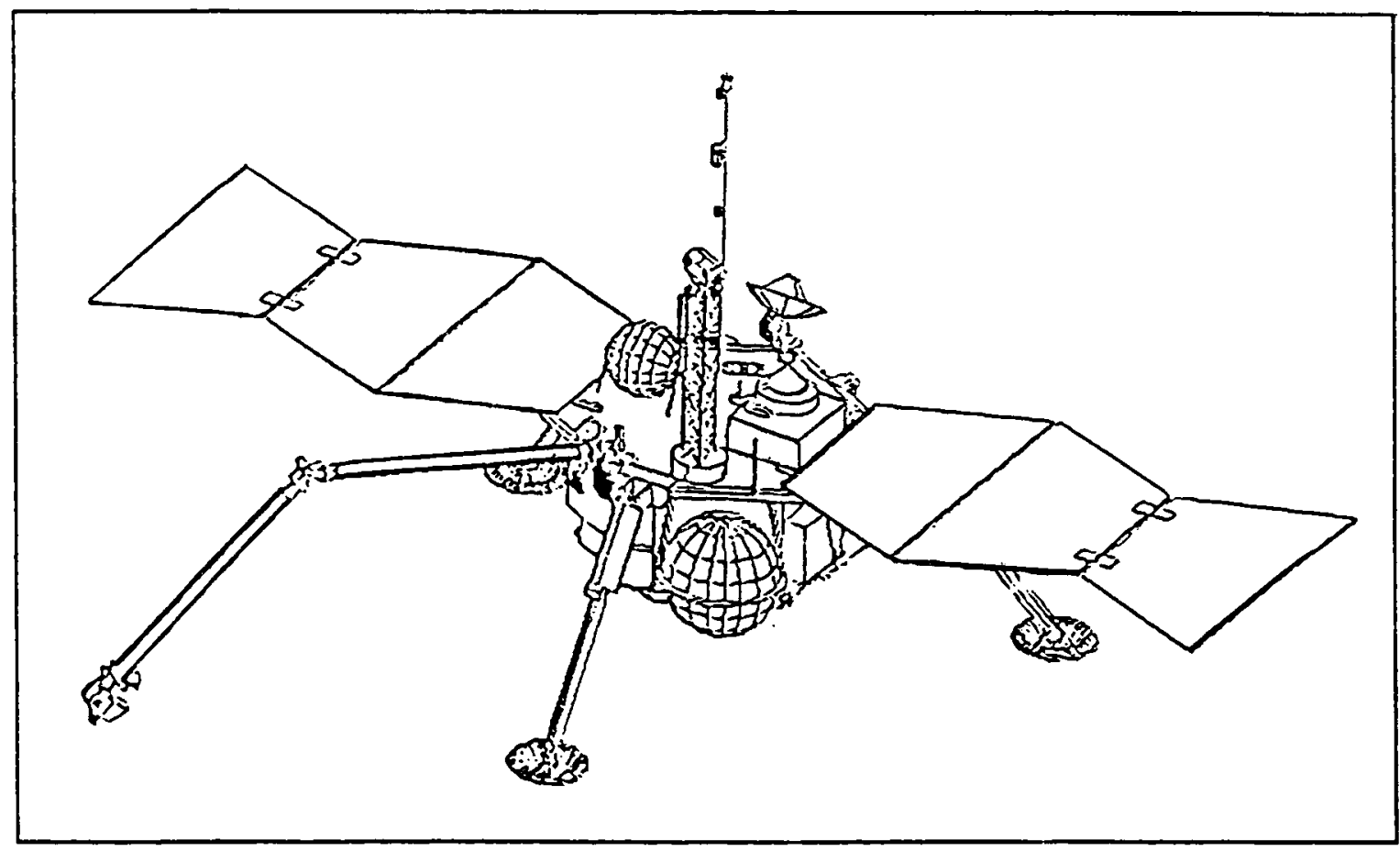

Space Studies. Board

National Research Council 


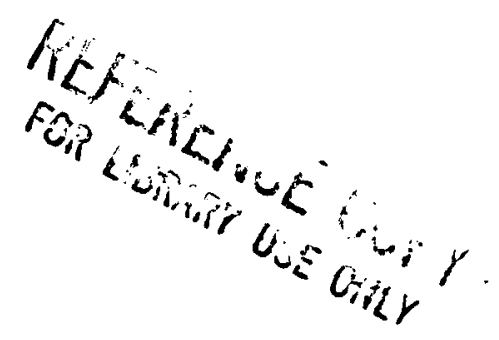

\section{Review of NASA's Planned Mars Program}

\section{Committee on Planetary and Lunar Exploration}

Space Studies Board

Commission on Physical Sciences, Mathematics, and Applications

National Research Council

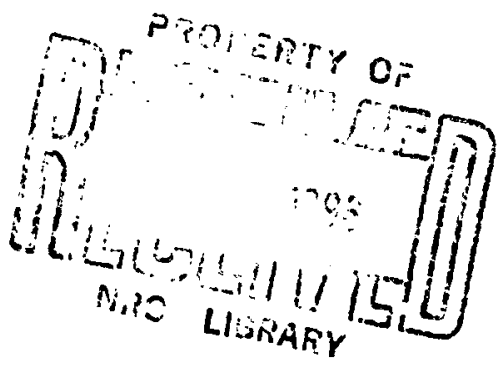

NATIONAL ACADEMY PRESS

Washington, D.C. 1996 
NOTICE: The project that is the subject of thiv report was approved by the Governing Board of the National Reseurch Council. whose members are drawn from the council, of the National Academ! of Sciences, the National Academy of Enginecring, and the Institute of Medicine. The membirs of the committee responsible for the report were chosen for their special competences and with regard for appropriate balance.

This sepon has been reviewed by a group wher thall the authors according to procedures approved by a Repor Review. Commutte convisting of members of the National Academy of Sciences. the National Academy of Engineering. and the Institute of Medicine.

The National Academy of Sciences is a private. nomprofit. Als grepetuating ixciety of divunguished scholars engaged in scientific and enginecring rescarch. dedicated to the furtherance of vierice and technology and to their use for the general welfare. Cpon the authority of the chaner granted to it by the Congress in 1863, the Academy has a mandate that requires it to advise the federal govermment on scientific and technical matters. Dr. Bruce Albers is president of the National Academy of Sciences.

The National Academy of Engineering was established in 1964, under the charter of the National Academy of Sciences. as a parallel organization of outstanding engineers. It is autonomous in its administration and in the selection of its members. sharing with the National Academy of Sciences the responsibility for advising the federal government. The National Academy of Enginesring also sponsors engineering programs aimed at meeting national needs, encourages education and research. and recugnizes the superior achievements of engineers. Dr. William A. Wulf is interim president of the Natuonal Academy of Engineering.

The Institute of Medicine was established in 1970 by ...e National Academy of Sciences to secure the services of eminent members of appropriate professions in the examination of policy matters perraining to the health of the public. The Institute acts under the responsibility given to the National Academy of Sciences by its congressional chaner to be an adviser to the federal government and. upon its own initiative. to identify issues of medical care, rescarch, and education. Dr. Kenneth 1. Shine is president of the Institute of Medicine.

The National Research Council was organized by the National Academy of Sciences in 1916 to associate the broad community of science and technology with the Academy's purposes of furthering knowledge and advising the federal government. Functioning in accordance with general policies determined by the Academy, the Council has become the principal operatung agency of both the National Academy of Sciences and the National Academy of Engineering in providing services to the government. the public. and the scientific and engineering communities. The Council is administered jointly-by both Academies and the Institute of Medicine. Dr. Bruce Alberts and Dr. William A. Wulf are charman and interim vice chairman. respectively. of the National Research Council.

Suppon for this project was provided by Contract NASW 4627 between the National Academy of Sciences and the National Aeronautics and Space Administration.

Cover: Diagram of the Mars Surveyor program's 1998 Mars lander. (Countesy of the Jet Propul. sion L:boratory. I

Copies of this repon are ar ailable from

Space Studies Board

National Research Council

2101 Constrtution Avenue, N.W.

Washington. D.C. 20418

Copynght 1996 by the National Academy of Sciences. All rights reserved.

Printed in the Lnited States of Amenca 


\section{COMMITTEE ON PLANETARY AND LLNAR EXPLORATION}

JOSEPH A. BURNS, Cornell University, Chair

RONALD GREELEY, Arizona State University, Successor Chair

JAMES ARNOLD iIniversity of Califormia, San Diego

FRANCES BAGE A AL, University of Colorado

JEFFREY R. BAR JES, Oregon State University

GEOFFREY A. BRIGGS, NASA Ames Research Center

MICHAEL H. CARR," U.S. Geological Survey

PHILIP R. CHRISTENSEN, Arizona State University

RUSSELL DOOLITTLE, University of California, San. Diego

JAMES L. ELLIOT;" Massachusetts Institute of Technology

HEIDI HAMMEL, Massachusetts Institute of Technology

JOHN F. KiRRIDGE.* University of Califomia, San Diego

BARRY H. MAUK," Applied Physics Laboratory

GEORGE McGILL, University of Massachusetts, Amherst

WILLIAM B. McKINNON, " Washington University

HARRY McSWEEN, University of Tennessee

TED ROUSH, San Francisco State University

JOHN RUMMEL, Marine Biological Laboratory

GERALD SCHUBERT, University of California, Los_Angeles

EUGENE SHOEMAKER, Lowell Observatory

DARRELL F. STROBEL, Johns Hopkins University

ALAN T. TOKUNAGA, University of Hawaii

ROGER YELLE, Boston University

MARIA T. ZUBER, Massachusetts Institute of Technology

Staff

DA VID H. SMITH, Study Director

ALTORIA B. ROSS, Senior Program Assistant -

"Term expired in 1995.

iii 
CL.ALDE R. CANIZARES, Massachusetts Institute of Technology. Chair JOHN A. ARMSTRONG. IBM Corporation (retired)

JAMES P. BAGIAN、 Environmental Protection Agency

DANIEL $N$. BAKER, Lniversity of Colorado

LAWRENCE BOGORAD, Harvard Lniversity

DONALD E. BROWNLEE, Lniversity of Washington

JOSEPH A. BLRNS, Comell Lniversity

JOHN J. DONEGAN. John Donegan Associates, Inc.

ANTHONY W. ENGLAND, Lniversity of Michigan

DANIEL. J. FINK, D.J. Fink Associates, Inc.

MARTIN E. GLICKSMAN. Rensselaer Polytechnic Institute

RONALD GREELEY, Arizona State L'niversity

BILL GREEN. former member. L.S. House of Representatives

HAROLD J. GLY; " Lniversity of California. San Diego

NOEL W. HIN.NERS. Lockheed Martin Astronautics

JANET G. LUHMANN. Lniversity of California, Berkeley

JOHN H. McELROY, Lniversity of Texas, Arlington

ROBERTA BALSTAD MILLER, Consortium for International

Earh Sciences Information Networks

BERRIEN MOORE III, Liniversity of New Hampshire

MARY JANE OSBORN, Lniversity of Connecticut Health Center

SIMON OSTRACH, Case Westem Reserve University

CARLÉ M. PIETERS, Brown Lniversity

JLDITH PIPHER, " University of Rochester

MARCIA J. RIEKE, Lniversity of Arizona

ROLAND SCHMITT, Clifton Park, New York

JOHN A. SIMPSON, University of Chicago

ARTHLR B.C. WALKER, JR.;" Stanford University

ROBERT E. WILLIAMS, Space Telescope Science Institute

MARC S. ALLEN, Director

-Former member. 
ROBERT J. HERMANN, United Technologies Corporation. Chair PETER. M. BANKS. Environmertal Research Institute of Michigan SYLVIA T. CEYER, Massachusetts Institute of Technology L. LOUIS HEGEDUS, North Bethesda, Maryland JOHN E. HOPCROFT, Comell University RHONDA J. HUGHES. Bryn Mawr College SHIRLEY A. JACKSON, U.S. Nuclear Regulatory Commission KENNETH 1. KELLERMANN, National Radio Astronomy Observatory KEN KENNEDY, Rice University THOMAS A. PRINCE, California Institute of Technology JEROME SACKS, National Institute for Statistical Sciences L.E. SCRIVtEN, University of Minnesota LEON T. SILVER, Califomia Institute of Technology CHARLES P. SLICHTER. University of Illinois at Urbana-Champaign ALVIN W. TRIVELPIECE. Oak Ridge National Laboratory SHMUEL WINOGRAD, IBM T.J. Watson Research Center CHARLES A. ZRAKET, The MITRE Corporation (retired)

NORMAN METZGER, Executive Director 


\section{Contents}

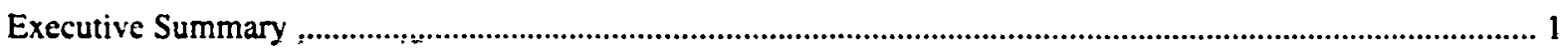

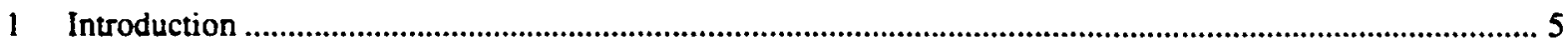

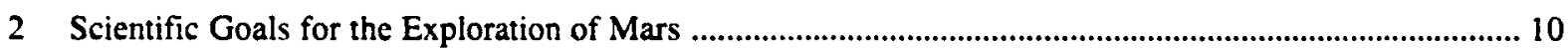

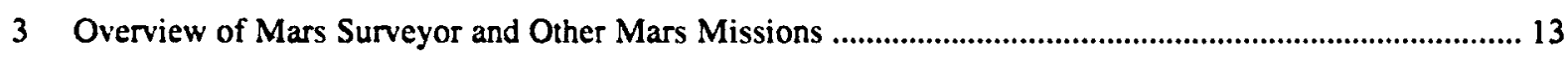

4 Key Issues for NASA's Mars Exploration Program ..................................................................................... 22

5 Assessment of the Scientific Potential of NASA's Mars Exploration Program ........................................... 28 


\section{Executive Summary}

Although Mars has been a primary target for space science missions over the past three decades, the record of success in the last few years has been poor. Indeed there has not been a completely successful Mars mission since the Viking project in the late 1970s. The failure of the Mars Observer mission in 1993 was a particularly hard blow for the planetary science community, because this spacecraft was scheduled to address many of the highestpriority investigations of the Red Planet. To recover from the loss of Mars Observer, NASA initiated Mars Surveyor, an extended program aimed at sending two small spacecraft to Mars during every launch opportunity between now and 2005. Mars Surveyor is cost-capped at $\$ 156$ million (including operations and launch vehicles) per year, and its announced goals are the study of martian climate, life. and "resources." The first mission, the 1050-kg Mars Global Surveyor, will be launched in November 1996 and will carry duplicates for much of Mars Observer's payload. A Discovery mission, Mars Pathfinder, consisting of a $360-\mathrm{kg}$ lander and a $10-\mathrm{kg}$ roving vehicle, will also be sent to Mars during this launch window. Subsequent missions in the Mars Surveyor prcgram. are expected to carry the remaining two instruments from Mars Observer and to conduct more complex observations, both on the surface and from orbit, perhaps in cooperation with international partners.

Given that Mars is one of the highest-priority objects for study identified in the Committee on Planetary and Lunar Exploration's (COMPLEX's) 1994 repon, An Integrated Strategy for the Planetary Sciences: 1995-2010,1 the Space Studies Board asked COMPLEX to review whether the Mars Surveyor and Mars Pathfinder programs, as presently conceived, satisfy the highest priorities for understanding Mars as provided in the committee's Integrated Strategy. Given that Mars Surveyor's "smaller-faster-cheaper" philosophy is very different from that of past NASA planetary missions, the current report's emphases concern not just the planned scientific objectives but also the effectiveness of using numerous, small missions with focused goals to explore Mars; COMPLEX does not assess the specific details of the program, which, especially in the out-years, is more conceptual than specific.

A complete exploration of Mars would require measurements of the planet's atmosphere, soil, rocks, and interior, as well as the surrounding near-Mars space environment. The missions in the Mars Surveyor program should be able to conduct fruitful experiments on the characteristics of the soil and atmosphere, since these are everywhere available. If a network of miniature meteorology stations were emplaced, then a major objective of atmospheric science could be accomplished. While studies of Mars's upper atmosphere are currently absent from the Mars Surveyor program, many of this field's objectives might be achieved through NASA's planned paricipation in Japan's Planet B mission.

Cost and payload limitations imposed on Mars Surveyor's small landers might prevent the flight of advanced 
rovers capable of adequate sampling of the rock record. Because evidence for past climate changes and ancient life, if any, is most likely embcdded in the rocks, this is a major shortcoming. Sounding of the interior requires simultaneous operation of at least three widely spaced scismology stations. This may be accomplished in the Mars Surveyor program as currently defined only if sophisticated landers, having less mass than Mars Pathfinder, can be developed: if not, it may become feasible in cooperation with the European Space Agency. A coordinated program with the Russians, in which they land an advanced rover, may alleviate the problem of access to solid rocks; altematively NASA might develop advanced rovers on its own.

The missions currently planned do, within the Mars Surveyor program, have the potential of adding significantly to our understa'lding of Mars. Not only does Surveyor recover essentially all of Mars Observer's objectives, which are essential first steps according to the Integrated Strategy; but it alsu initiates a challenging program of surface exploration by small landers with highly focused science goals. In addition, some aspects of COMPLEX's strategy not addressed by Mars Surveyor are being or can be addressed by judicious cooperation with iriternational parners.

Spacecraft instrumentation is of great concern to COMPLEX. Because the Mars Surveyor program is on a fast track, there is inadequate time to allow some instruments to be developed to a sufficient level so that risk is small. Furthermore, although plans are being formulated outside the Surveyor program to reduce significantly the size of spacecraft, schemes to produce complementary and innovative miniaturized instruments are absent. Yet the success of the Mars Surveyor program will depend to a considerable extent on how sophisticated a payload can be flown within the program's stringent constraints on cost, schedulc, and mass. Because funding within the Surveyor program is too limited to foster significant development of so-called microinstruments, the scientific objectives of the program could be seriously undermined unless instrument development is externally supported. Thus, to ensure important scientific advancement either microinstrument development should become an essential component of NASA's New Millennium spacecraft technology program, or some activity comparable to the existing Planetary Instrumentation Definition and Development Program (PIDDP) should be initiated for microinstruments.

A longer-term concern is that as the program progresses it may become increasingly difficult to make major discoveries with the smai: landers currently envisaged. In any transition to more ambitious missions, including sample return, long-range $:-$ is equipped with significant instrumentation may be necessary for the definitive resolution of questions concerning past climates and history.

Despite these potential problems, the Mars Surveyor program (as long as NASA continues to interpret "resources" to include martian geology, geophysics, and geochemistry) provides a major opportunity to broaden and deepen our understanding of Mars-its atmosphere a!dd climate, its geochemistry and geophysics, and, to a somewhat lesser extent, its present and past potential for harboring life. Because the program includes many launches over many years, it-like the Discovery program-can, in principle, afford to be bolder and take greater scientific and technological risks than the more restrictive programs of the past. This opportunity for innovation should not be missed. However, substantial technological innovation will occur only if NASA adopts a new attitude toward risk management. As COMPLEX has emphasized previously, the ability to accept the occasional but inevitable disappointments that come with trying innovative solutions must be an integral feature of NASA's emphasis on small missions. ${ }^{2}$ While long-established, hard-earned attitudes cannot be expected to change ovemight, the smaller-faster-cheaper approach will demand that some additional risk be accepted.

In summary, although NASA's Mars exploration program does not meet ali scientific requirements (e.g., in aeronomy, internal structure, and seismic activity, or with respect to a sophisticated exploration for extant oi extinct life), it will be broadly consistent with a significant subset of the scientific priorities outlined in the Integrated Strategy provided that:

- The program of global mapping planned to start with Mars Global Surveyor in 1996 is completed by flying tre Pressure Modulator Infrared Kadiometer in 1998 and the Gamma-Ray Spectrometer in 2001;

- The mobility of landers and other vehicles is enhanced beyond that exemplified by Mars Pathfinder's rover so as to allow measurements to be made on a wide variety of rocks and terrains; 
- The Mars Surveyor program is kept flexible so that it can respond to scientific and technological opportunities and can encompass a broad range of mission modes;

- International partners continue to be involved in order to supplement U.S. capabilities and leverage U.S. resources committed to the program;

- An aggressive program for development of miniaturized instruments is initiated; and

- The goal of returning samples of martian soil, atmosphere, and, most importantly, rocks remains a central element of NASA's planning.

\section{REFERENCES}

1. Space Studics Board. National Research Council. An Integrated Strategy for the Planetan Sciences: 1995-2010, National Academy Press, Wrshing.un, D.C., 1994.

2. See, for example, Space Studies Board, National Research Council, The Role of Small Missions in Planetany and Lunar Exploration. National A'ademy Press, Washington, D.C., 1095, pp. 18-19. 


\section{Introduction}

The exploration of Mars has long been a prime scientific objective of the U.S. planetary exploration program. Yet no U.S. spacecraft has successfully made measurements at Mars since the Viking missions of the late 1970s. Mars Observer, which was designed to conduct global observations from orbit, failed just before orbit insertion in 1993. The Russian spacecraft Phobos 2 did succeed in making some observations of the planet in 1989, but it was designed primarily to observe Phobos, the innermost satellite of Mars; the spacecraft failed 2 months after insertion into Mars orbit during the complex maneuvers required to rendezvous with the martian satellite.

In fall 1996 NASA plans to launch Mars Pathfinder for a landing on the martian surface in mid-1997. This spacecraft is one of the first two missions in NASA's Discovery program that inaugurates a new style of planetary exploration in which missions are low-cost ( $<\$ 150$ million) and have very focused science objectives. As can be seen in the comparative data presented in Box 1, this mission is considerably smaller in terms of cost, mass, and scope than NASA's previous Mars missions.

NASA's FY 1995 budget initiated a continuing Mars exploration program, called Mars Survivor, that involves multiple launches of spacecraft as small as or smaller than Mars Pathfinder to Mars over the next several launch opportunities, which recur roughly every 26 months. The first mission in the program, Mars Global Surveyor, set for launch late in 1996, is intended to accomplish many of the objectives of the failed Mars Observer. Like the Discovery program, Mars Surveyor is a continuing series of low-cost missions, each of which has highly focused science objectives. See Box 1 for comparative details of those Surveyor missions currently defined.

Around the same time that the Mars. Surveyor series was chosen as the centerpiece of NASA's solar system exploration program, the Committee on Planetary and Lunar Exploration (COMPLEX) designated Mars as one of four scientific targets for emphasis in future studies. It was against this background that the Space Studies Board charged COMPLEX to review whether the Mars Pathfinder and Surveyor programs, as presently conceived, satisfy the highest priorities for understanding Mars as provided in its report, An Integrated Strategy for the Planetary Sciences: 1995-2010.1 The present document is COMPLEX's assessment of the scientific potential of NASA's new approach to Mars exploration. This assessment considers how well the scientific objectives of the Mars Surveyor program match those of the Integrated Strategy; it also addresses some advantages and disadvantages of the smaller-faster-cheaper approach to the exploration of Mars. The capabilities of the various instruments are not discussed in detail since the Mars Observer instruments, all of which are scheduled for reflight, have already been asses: $:$ by COMPLEX ${ }^{2}$ and later instruments are, in general, not yet well defined. 


\section{Box 1 NASA Mars Missions, 1964 to 2005 \\ Past}

Mariner-Mars 1964 (Mariners 3 and 4): Failure of its launch shroud to open doomed Mariner 3 within minutes of its launch. Mariner 4, however, performed the first flyby of Mars. Its instruments returned the first images of Mars's cratered surface and data on the planet's magnetic and trapped-particle environments. Four additional instruments were dedicated to space-physics measurements made during the journey to Mars.

- Mission type-2 flybys with 7 instruments each

- Launch date-November 1964

- Arrival date-July 1965

- Mass-261 kg (dry), 27 kg (payload)

- Cost ${ }^{1}$-ss

- Operations cost-?

- Launch vehicle-Atlas-Agena

Mariner-Mars 1969 (Mariners 6 and 7): The pioneering observations of Mariner 4 were greatly extended by this pair of flyby spacecratt. Both were equipped with sophisticated remote-sensing instruments (including wide- and narrow-angle television cameras, an infrared radiometer, and ultraviolet and infrared spectrometers) mounted on a scan platform. They returned a total of some 200 photographs compared with approximately 20 from Mariner 4.

- Mission type-2 flybys with 5 instruments each

- Launch dates-February and March, 1969

- Arrival dates-July and August, 1969

- Mass-384 kg (dry), $75 \mathrm{~kg}$ (payload)

${ }^{1}$ Costs are based on data Supplied by NASA for use in COMPLEX's recent report, The Role of S.nall Missions in Planetary and Lunar Exploration (Space Studies Board, National Research Council, National Academy Pross, Washington, D.C., 1995, p. 6), and have been supplemented, where necessary, with new data fumished by the Jet Propuision Laboratory. Costs are in 1996 dollars and are expressed in terms of cost categories. These categories are as follows:

- \$-Small- $\$ 100$ million

- SS-Intermed fto-> $\$ 100$ million but $<5500$ million

- $\$ S \$-$ Large $>\$ 500$ million but $<\$ 1$ billion

- SSSS-Flagship->SI billion but $<\$ 4$ billion

Operating costs afe indicated in a similar manner using the following categories:

- S-Small-\$25 million

- SS-Medium $\rightarrow \$ 25$ million but $<\$ 75$ million

- Sss-Largo $\rightarrow \$ 75$ million but $<$ :50 million

The superscripts plus $\left(^{+}\right)$and minus $(7)$ are used to ind cate the high and low ends of each calegory. A question mark (?) indicates mat COMPLEX could not identity the cost. 
- Cost-S\$+

- Operations cost-?

- Launch vehicle-Atlas-Centaur

Mariner-Mars 1971 (Mariners 8 and 9): Although Mariner 8 failed on launch, its twin (Mariner 9) became Mars's first artificial satelite. Despite the loss of Mariner 8 , this extremely successful program revolutionized our understanding of martian geologic and climatic history and defined the context in which all subsequent Mars missions were designed.

- Mission type-2 orbiters with 4 instruments each

- Launch date-May 1971

- Arrival date-November 1971

- Lifetime at ME. 3-11 months

- Mass-998 kg (wet), $544 \mathrm{~kg}$ (dry), $82 \mathrm{~kg}$ (payload)

- Cost- $\$ \$^{+}$

- Operations cost-\$\$\$

- Launch vehicie-Atlas-Centaur

Viking (Viking 1 and 2): This highly capable and expensive program was responsible for the first two successful Mars landings, the only two so far, and the initial search for martian life. Although the lifedetection experiments gave ambiguous results, the long-lived Viking landers and especially the orbiters retumed a wealth of information about martian meteorology and geology.

- Mission type-2 orbiters with 4 instruments each and 2 landers with 13 instruments each

- Launch dates-August and September, 1975

- Arrival dates-June and August, 1976 (orbit), July and September, 1976 (surface)

- Lifetime at Mars-50 and 23 months (orbiters 1 and 2), 76 and 42 months (landers 1 and 2)

- Landing system-Parachutes and retrorockets

- Landing site-Chryse Planitia $\left(22.3^{\circ} \mathrm{N}, 48.0^{\circ} \mathrm{W}\right)$, Utopia Planitia $\left(47.7^{\circ} \mathrm{N}, 225.7^{\circ} \mathrm{W}\right)$

- Mass-2330, 1170, 72 and 1043, 650, $65 \mathrm{~kg}$ (orbiter and lander: wet, dry, payload, respectively)

- Mobility-3-m arm attached to landers

- Cost- $\$ \$ \$ \$ \$^{+}$

- Operations cost-\$\$\$

- Launch vehicle-Titan III-Centaur

Mars Observer: Originally called the Mars Geosciences/Climatology Orbiter, this mission was intended to initiate a proposed series of low-cost, Planetary Obsenver spacesraft. Mars Observer carried a suite of complex remote-sensing instruments to conduct intensive geophysical, geological, and climatological observations of Mars. It failed shortly before entering orbit around Mars.

- Mission type-1 orbiter with 7 instruments

- Launch date-September 1992

- Arrival date-August 1993

- Lifetime at Mars - 0 years (actual), 3 years (projected)

- Mass-2573 kg (wet), $1227 \mathrm{~kg}$ (dry), $156 \mathrm{~kg}$ (payload)

- Cost-\$\$\$

- Operations cost-\$\$ (projected)

- Launch vehicle=-Titan III-TOS 
Box 1 continued

\section{Future}

Mars Pathfinder: One of the inaugural missions in the Discovery series of low-cost planetary spacecraft, Mars Pathfinder will feature the first use of a direct-entry trajectory, an airbag landing system, and the deployment of a minirover. Together, the lander and minirover will carry imaging systems, a meteorology package, and an alpha-proton-x-ray spectrometer.

- Mission type-1 lander with 3 instruments

- Launch date-December 1996 (projected)

- Arrival date-July 1997 (projected)

- Lifetime at Mars-30 days to 1 year (projected)

- Landing system-Parachutes, retrorockets, and airbags

- Landing site-Ares and Tiu Vallis $\left(19.5^{\circ} \mathrm{N}, 32.8^{\circ} \mathrm{W}\right.$ ) (planned)

- Mobility-Minirover Sojourner ${ }^{2}$

- Mass-570 kg (wet), $325 \mathrm{~kg}$ (lander $\left.{ }^{3}\right), 20 \mathrm{~kg}$ (payload)

- Cost-\$\$

- Operations cost-\$

- Launch vehicle-Delta II

Mars Global Surveyor: The first of a decade-long series of cost-constrained Mars missions, Mars Global Surveyor is designed to recover much of the science lost with the failure of Mars Observer by reflying five of its predecessor's seven instruments. Among the instruments to be flown are an imaging system, a thermal spectrometer, a laser altimeter, and a magnetometer. The radio system also has scientific functions.

- Mission type-1 orbiter with 5 instruments

- '.aunch date-November 1996 (projected)

- Arrival date-September 1997 (projected)

- Lifetime at Mars-2 years plus 3 more as communications relay (projected)

- Mass-1050 kg (wet), $670 \mathrm{~kg}$ (dry), $75 \mathrm{~kg}$ (payload)

- Cost-S\$-

- Operations cost- $\$^{+}$

- Launch vehicle-Delta II

Mars Surveyor 1998: Unlike Viking, the orbiter and lander constituting the second and third flights in the Mars Surveyor series will be launched independently and follow separate trajectories to Mars. The orbiter will refly Mars Obsenver's Pressure Modulator Infrared Radiometer. It will also carry an integrated wideand medium-angle imager. The lander will be equipped with a descent imager, a lidar, and an integrated science package consisting of a mast-mounted stereo-imager, a meteorological package, a thermal/ evolved gas analyzer, and a robotic arm. The lander will also deploy two microprobes prior to entry.

- Mission type-1 orbiter with 2 instruments

- Launch date-December 1998 (projected)

- Arrival date-September 1999 (projected)

- Lifetime at Mars-2 years plus 2 more as communications relay (projected)

- Mass-565 kg (wet), $338 \mathrm{~kg}$ (dry), $46 \mathrm{~kg}$ (payload)

2 Soe Table 1 in Chapter 3 for spacifications.

3Lander ory mass excludes heat shield and parachute masses, but oces incluote airbags. 
- $\operatorname{Cost}^{4}-\$+$

- Operation: $\operatorname{cost}^{5}-\$^{-}$

- Launch ve.ricle-Med-Lite

- Mission type-1 lander with 5 U.S. and 1 Russian instruments

- Launch date-January 1999 (projected)

- Arrival date-December 1999 (projected)

- Lifetime at Mars-86 to 146 days (projected)

- Landing system-Parachutes and retrorockets

- Landing site-Edige of southern polar cap, $76^{\circ} \mathrm{S}, 210^{\circ} \mathrm{W}$ (planned)

- Mobility-2-m robotic arm (with microscope camera on tip)

- Mass-504 kg (wet), $331 \mathrm{~kg}$ (dry6), $22 \mathrm{~kg}$ (payload), $30 \mathrm{~kg}$ (2 miniprobes)

- Cost $^{7}-s^{+}$

- Operations $\cos ^{8}-\$$

- Launch vehicle-Med-Lite

Mars Surveyor 2001: Undefined at present. Mars Observer's remaining instrument, the Gamma-Ray Spectrometer, will presumably be reflown during this launch opportunity.

Mars Surveyor 2003: Although this mission is currently undefined, the Mars Communications/Aeronomy Orbiter and NASA's contribution (three or four small landers) to the European Space Agency's proposed Intermarsnet mission could possibly be flown during this launch opportunity.

Mars Surveyor 2005: This launch window represents the earliest possible opportunity for a U.S. sample return mission. The technical feasibility of this goal, within the context of the Mars Sunveyor program as currently defined, is far from clear.

4The total development cost (through launch plus 30 days) for both of the Mars Surveyor 1998 missions is capped at $\$ 184$ million. COMPLEX has arbitranily divided this amount equally between the orbiter and lander.

${ }^{5}$ COMPLEX has arbitrarily divided the total operations cost for this pair of missions equaliy between the orbiter and the lander.

${ }^{6}$ Lander dry mass excludes heat shield and parachute masses, but does include propellant tanks and associated plumbing.

7 The total development cost (through launch plus 30 days) for both of the Mars Surveyor 1998 missions is capped at $\$ 184$ million. COMPLEX has artitrarily divided this amount equally between the ortiter and lander.

BCOMPLEX has arbitranily divided the total operations cost for this pair of missions equally between the orbiter and the lander.

\section{REFERENCES}

1. Space Studies Board, National Research Council, An Integrated Strategy for the Planetury Sciences: 1995-2010, National Academy Press, Washingtor. D.C., 1994.

2. Letter report regarding an assessment of the impact on integrated science retum from the 1992 Mars Observer mission, from the Committee on Planetary and Lunar Exploration to Geoffrey A. Briggs (NASA). July 12, 1988. 


\section{Scientific Goals for the Exploration of Mars}

The Space Studies Board's key report outlining the principal scientific issues in the planetary sciences is $A n$ Integrated Strategy for the Planetary Sciences: 1995-2010.1 After summarizing current knowledge about the solar system and the key remaining scientific questions, the Integrated Strategy lists Mars among its four highest-priority objects for further study, the other targets being comets, Jupiter, and planetary systems around other stars. The Integrated Strategy describes a series of important measurements to be made at Mars. Strategies for the scientific exploration of Mars have also been written by other panels, including the Mars Science Working Group ${ }^{2}$ and the International Mars Science Working Group. ${ }^{3}$ All these reports identify the same three science themes for Mars exploration, namely:

- The search for indigenous life or evidence of past life,

- Atmospheric dynamics and climate change, and

- The evolution of the surface and interior.

COMPLEX now briefly elaborates on these topics and describes observations that, according to the Integrated Strategy, will best elucidate the primary scientific questions. Previous reports have defined specific measurement requirements arising from the scientific objectives (see below) relating tosthese themes. ${ }^{4-6}$ It is not necessary to repeat here all those requirements; clearly, without capable instruments, Mars Surveyor will not accomplish the scientific goals that are the program's rationale.

\section{LIFE}

There is increasingly compelling evidence that Mars was, and may still be, water-rich and that it has undergone major changes in its climate. This evidence, coupled with indications from molecular phylogeny of the conditions under which primitive life may have existed on Earth, has heightened interest that life may also have started on Mars. Nevertheless, survival of living forms on the present surface of Mars is considered highly improbable. ${ }^{7.8}$ Accordingly, much of the emphasis in Mars exploration is on a search for evidence of past life. If some form of life did start on Mars in the distant past, it may have survived in protected niches such as longlived volcanic vents or deep aquifers. ${ }^{9}$ In order to better judge whether living forms might have arisen on Mars and where to search for evidence of them, we need to better understand climatic history: the inventory and 
distribution of volatiles and biogenic elements; and the locations and characteristics of potential pas: habitats such as hydrothermal systems and lakes. Even the likely case that life never developed on Mars is interesting by comparison with the terrestrial example: How did conditions differ for the two planets?

The optimum strategy for the biologic exploration of Mars, endorsed by COMPLEX and other groups, is to focus first on global reconnaissance to better assess past surface conditions and planet-wide inventories of water as well as other volatiles and to identify promising sites where such materials might be available. Emphasis would then shift to surface exploration of these favorable locations to seek more clear-cut evidence of past conditions, and to search for more direct confirmation of past life such as the presence of biogenic elements and compounds, and anomalous isotopic fractionations. Ultimately, returned samples will be needed for definitive analysis in terrestrial laboratories.

\section{ATMOSPHERIC DYNAMICS AND CLIMATE CHANGE}

COMPLEX's goals for atmospheric science at Mars include two different but connected themes. The first concerns the dynamics and chemistry of the present martian atmosphere and how it compares with Farth's gaseous envelope; the second is to understand the evolution of the atmosphere and, in particular, past climatic conditions. In order to characterize the atmosphere's general circulation, systematic high-resolution soundings of the atmosphere for temperature, dust, water vapor, and aerosols must be made over at least 1 martian year. In addition, measurements of pressure, wind, humidity, and opacity need to be made at a number of widely distributed surface stations for at least 1 martian year, during the same period when vertical temperature profiles are being monitored from orbit. Between 15 and 20 stations, distributed over the surface and at various elevations sufficient to ensure that the characteristic separation of any two stations is no more than a planetary radius, appear to be the minimum necessary to acquire interpretable meteorological data.

Mars may have undergone modest climatic changes in the recent geologic past, but larger variations in the more distant past. Evidence for the more recent changes are probably best p.eserved in the polar layered deposits, and so an exploration program should include a means of characterizing these deposits. Information on more ancient. climates may be derived in various ways: from geomorphic evidence of past fluvial action and erosion rates, from the composition of gases trapped in ancient rocks, from the characteristics of sediments deposited in climate-sensitive environments such as lakes, from the mineralogy of weathering products, and so forth. An exploration strategy should, therefore, include schemes for identifying and locating climate-sensitive features as well as the means for characterizing and possibly sampling the relevant deposits. The atmosphere's composition-in particular the isotopic ratios for $\mathrm{H}, \mathrm{C}, \mathrm{N}, \mathrm{O}$, and the noble gases-also provides clues about its evolution. In addition, measurements of the escape rates of upper-atmospheric species are useful in constraining models of past climates.

\section{EVOLUTION OF SLRFACE AND INTERIOR}

The decipherment of the origin and evolution of the solid planet, and its comparison with Earth's evolution, are both important goals in COMPLEX's strategy for Mars exploration. The surface's chemistry, lithology, and morphology result from a variety of internal (volcanism and tectonism) or external (impacts) processes, or interactions with the atmosphere (erosion and sedimentation). Any interpretation of the record will require global surveys of the chemistry, mineralogy, and morphology from orbit, followed by detailed surface measurements at locations of special interest (e.g., lake beds or hydrothermal deposits) that have been identified from the orbital data. Many of the critical measurements needed to unravel the geologic history-such as ages, determination of stable isotopes, and measurement of trace elements-at present seem to require sample return.

The planet's interior provides information ibout how the solid body accumulated, differentiated, and evolved. Orbital measurements of the gravitational, topographic, and magnetic fields provide valuable constraints on interior properties, primarily about shallow structures. To specify core and mantle properties, as well. as to locate present tectonic and volcanic activity, a seismic network will need to be emplaced. 


\section{REFERENCES}

1. Space Studies Board. National Research Council. An Integrated Strategy for the Planetary. Sciences: 1995-2010. National Acaderny Press. Washington, D.C., 1994

2. NASA. Mixrc Science Working Group, A Strategy for the Scientifc Exploration of Mars. PL D-8211. Jet Propulsion Laboratory. Pasadena. Calif.. February 1991.

3. International Mars-Science Working Group. "An International Strategy for the Exploration of Mars." Planetary and Space Science. in press.

4. Space Science Board. National Research Council. Strategy for Exploration of the Inner Planets:-1977-1987. National Academy of Sciences. Washington, D.C.. 1978.

5. Space Studies Board. National Research Council. 1990 Update of Strategy for Exploration of the Inner Plantets. National Academy Press. Washington, D.C.. 1990.

6. Space Studies Board. National Research Council. An Integrated Strategy for the Planetan. Sciences: 1995-2010. National Academy Press. Washington, D.C.. 1994.

7. Space Studies Board. National Research Council, The Search for Life's Origins: Progress and Future Directions in Planetary. Biolog: and Chemical Evolution. National Academy Press. Washington. D.C., 1990.

8. Space Studies Board. National Research Council. Biological Contamination of Mars: Issues and Recommendations. National Acad. emy Press, Washington. D.C.. 1992.

9. Exobiology Program Office. Exobiological Strategy for Mars Exploration, NASA, Washington, D.C., 1995. 


\section{Overview of Mars Surveyor and Other Mars Missions}

In this chapter COMPLEX desciibes NASA's plans for the exploration of Mars by its own spacecraft and by U.S. participation in international missions. Throughout this description, COMPLEX points out how these planned missions contribute to the scientific priorities for the study of Mars listed in COMPLEX's Integrated Strategy. COMPLEX has already assessed the Mars Observer instruments scheduled to be reflown on Mars Surveyor missions in 1996, 1998, and 2001.' It has not quantitatively assessed the capabilities of the instrument payloads to fly on later Mars Surveyor missions because, in general, they are not yet specified in sufficient detail. Once these missions are well defined, instrument capabilities must be assessed against previously stated requirements.

Mars Surveyor is a congressionally authorized program of Mars exploration that will start with the 1996 launch of Mars Global Surveyor and that will last for at least a decade. The program's funding is strictly capped at approximately $\$ 100$ million per year, with an additional annual sum of $\$ 20$ million for operations and $\$ 36$ million for launch vehicles. At the program's initiation, NASA placed a variety of nonscientific constraints on Mars Surveyor. ${ }^{2}$ More recently these "constraints" have become "guidelines." For example, NASA required that two launches must be made at each orbital opportunity (which recur every 26 months) and must (after 1996) use the proposed Med-Lite launch vehicle, which will have approximately half the capacity of the Deltas used to launch Mars Global Surveyor and Mars Pathfinder. Now NASA states that "if there are compelling reasons, a single launch ... may be acceptable for particular opportunities." ${ }^{.3}$ In addition, other essential components of the program include public outreach, support for education, development of new technologies, and preparation of the way for eventual human exploration. According to NASA, Mars Surveyor is to address three themes: life, climate, and resources, where the third is currently understood to include the origin and evolution of the solid planet. The role and history of water on Mars represent the common thread that unites these topics.

\section{LAUNCH OPPORTUNITY}

NASA will send a pair of spacecraft to Mars during the 1996 launch opportunity (Figure 1). The first, Mars Pathfinder, is not part of the Mars Surveyor program, but rather one of the inaugural missions in NASA's Discovery series of low-cost, focused science missions. The second mission, Mars Global Surveyor, is the initial element of the Mars Surveyor program. Russia has also scheduled a flight to Mars during this launch opportunity. Below COMPLEX describes each of these three missions. 

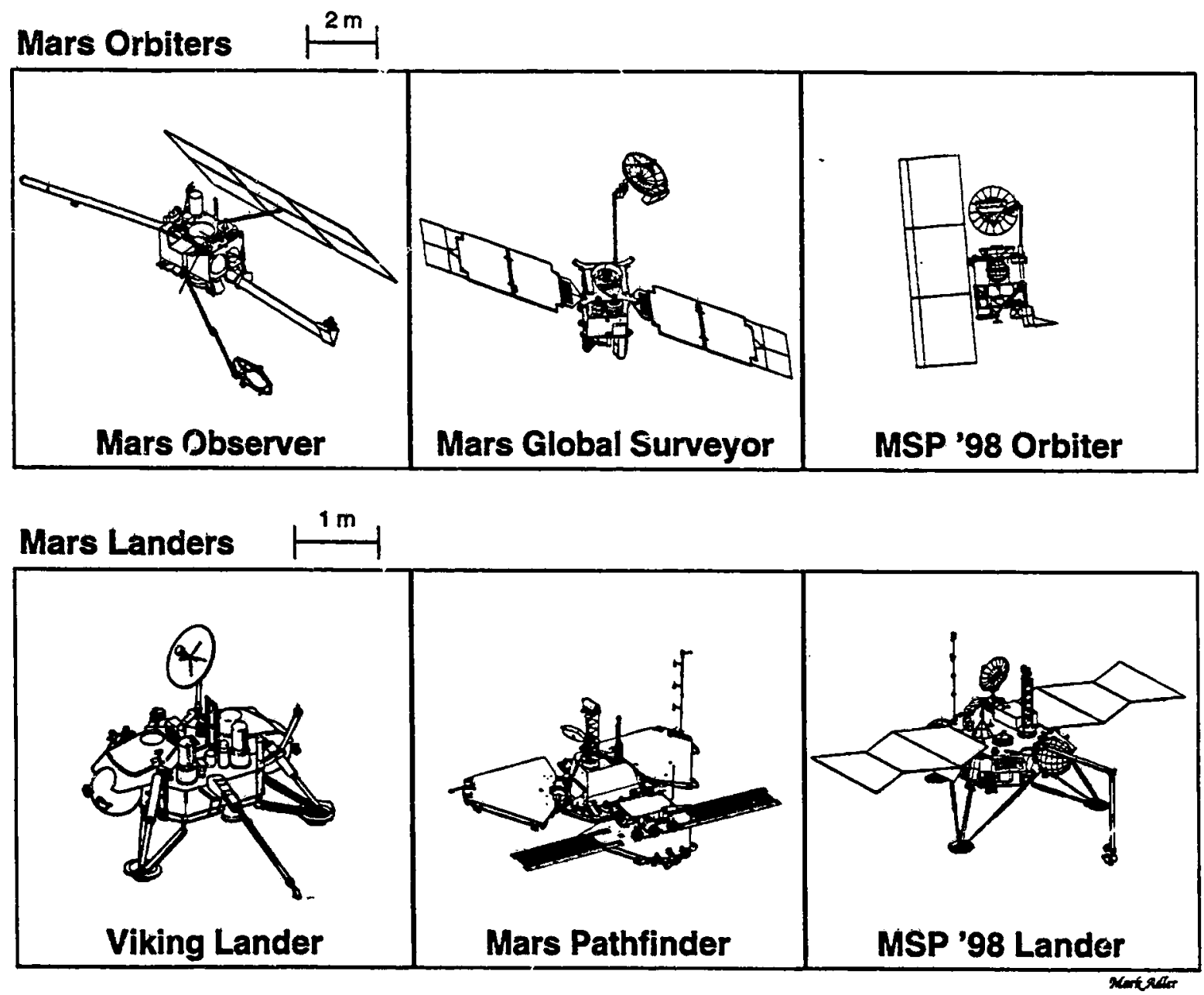

FIGURE 1 The relative sizes of past and future Mars orbiters and landers are apparent in these sketches. Although the orbiters are all approximately the same size, their masses are very different. Mars Observer's dry mass was approximately twice that of Mars Global Surveyor and fnur iimes that of the Mars Surveyor Program's (MSP's) 1998 orbiter. Similarly, the solar panels powering Mars Pathfinder and the MSP ' 98 lander make them seem to be as large as the nuclear-powered Viking. In reality, Viking's dry mass was approximately twice that of Mars Pathfinder and the MSP ' 98 lander. Note that the orbiters are drawn at a different. scale from the landers. Illustration courtesy of the Jet Propulsion Laboratory.

\section{Mars Pathfinder}

Mars Pathfinder was originally conceived primarily as an engineering test to develop an inexpensive entry, descent, and landing system for future Mars landers, and to pioneer ways of doing planetary missions at significantly lower costs than were typical of past endeavors. A secondary technical goal is to deliver and operate the semi-autonomous, solar-powered minirover, Sojoumer (see Box 2 and Table 1 for definitions and specifications), to demonstrate the mobile deployment of science instruments and to assess the effects of environmental conditions on the minirover's performance. Despite its technological emphasis, Mars Pathfinder has the potential to return significant, new scientific data. 


\section{Box 2 Rover Characteristics}

Large rovers are highly sophisticated vehicles, powered by radioisotope thermoelectric generators, that were considered in the context of various Mars sample retum and other mission concepts developed in the $1980 \mathrm{~s}^{1-4}$. They are, in general, quasi-autonomous and were conceived to be wide-ranging and capable of operating independently of their landing vehicle.

- Total mass $5-400$ to $1500 \mathrm{~kg}$

- Payload mass-35 to $150 \mathrm{~kg}$

- Range-0.1 to $10 \mathrm{~km} /$ day

- Communications-Directly to Earth or via an c. ¿. or

- Lifetime-Hundreds of days to years

Minirovers are more modest, battery- and solar-powered vehicles developed in the context of the austere Mars missions concepts that were devised in the early 1990s. The smaller vehicles in this category are, in general, dependent on their landers for communications and cannot travel far from their landing site. Mars Pathfinder's Sojourner and Russia's Marsokhod (see Table 1 for detailed spevifications) fall at, respectively, the lower and upper ends of this size category.

- Total mass-10 to $70 \mathrm{~kg}$

- Payload mass-2 to $20 \mathrm{~kg}$

- Range-Tens of meters per day

- Communications-Via lander or orbiter

- Lifetime-Tens of days

Microrovers are vehicles smaller than Sojourner that were designed to be compatible with the smaller landing vehicles baselined in the Mars Sunveyor program after Mars Pathfinder. Microrovers overlap with another family of vehicles, the instrument deployment devices (IDDs). These are small mechanisms designed to deploy a single instrument away from the parent lander. While IDDs can be equipped with a primitive form of autonomous navigation, their lifetime and ranges will be severely limited because they are so small that they will have trouble surviving nighttime temperatures of $-180 \mathrm{~K}$. Microrovers and IDDs may be the sole size of vehicle permissible for a NASA-only Mars program in the next decade.

- Total mass- 0.05 to $2 \mathrm{~kg}$

- Payload mass-0.01 to $0.5 \mathrm{~kg}$

- Range-10 to $20 \mathrm{~m}$

- Communications-Via lander

- Lifetime $<1$ day

Nanorovers are the current technological frontier in rover design. Such devices will probably be restricted to operating within view of a lander, and martian temperature extremes will almost certainly limit their lifetimes to less than 1 day.

- Total mass $<0.05 \mathrm{~kg}$

\footnotetext{
${ }^{1}$ National Aeroneutics and Space Administration (NASA), Solar System Exploration Committee, Planetary Exploration Through Year 2000: An Augmented Program, NASA, Washington, D.C., 1986

2Science Applications International Corporation (SAIC), Planetary Missions Performance Handbook, Volume IV: Mission Descriptions, SAIC-86/1853, SAIC. Schaumburg, Illinois, August 1986.

3john Niehoff, "Mars Rover/Sample Retum Mission Overview," presentation to Space Science Board Ad Hoc Study Group Feasibility Study of Joint Mars Sample Return Mission, April 28, 1987.

4European Space Agency (ESA), Mars Rover Mission: Interim Report of ESA Science and Technology Definition Team, SCI(87)2, ESA, Paris, April 1987.

${ }^{5}$ The boundaries of the various mass categories listed are, of course, arbitrary, and the particular values shown were chosen bechuse they reflect the masses of actual or conceptual vehicies considered for Mars exploration in recent decades.
} 
TABLE 1 Characteristics of Sojourner, Marsokhod. and a Strawman Advanced Minirover

\begin{tabular}{|c|c|c|c|}
\hline Characteristics & Sojourner & Marsokhod ${ }^{1}$ & $\begin{array}{l}\text { Strawman } \\
\text { Advanced } \\
\text { Minirover }\end{array}$ \\
\hline Mass $(\mathrm{kg})$ & 10 & 70 & $25-35$ \\
\hline Science payload mass (kg) & 2 & 15 & $5 \cdot 10$ \\
\hline Power (W) & 10 & $10 s$ & 25 \\
\hline Length $(\mathrm{m})$ & 0.65 & 1.5 & $1 . \theta$ \\
\hline Wheel diameter ( $\mathrm{m}$ ) & 0.13 & 0.3 & 0.1 \\
\hline Range (m/day) & $<60$ & $100 \mathrm{~s}$ & $<1000$ \\
\hline Position fixing $( \pm m)$ & $0.2(<10 \mathrm{~m}$ from lander $)$ & - & \pm 1000 (anywhere) \\
\hline Communications (Mbits/day) & 3 (via lander) & 10 to 20 (via orbiter) & 10 ( wia orbitcr) \\
\hline Rover landed mass fraction $(q)$ & 3 & - & 3 \\
\hline
\end{tabular}

${ }^{1}$ Based on information from NASA's Ames Research Center and on experiences in field testing Russia's Marsokhod vehicles.

2Based on specifications drawn up at NASA's Workshop on Mobility, held at Ames Research Center, July 19-20. 1995.

The mission profile calls for Mars Pathfinder to be launched on a Delta II booster in December 1996 and to follow a direct trajectory to Mars. Upon its arrival in July 1997, the spacecraft will decelerate through the upper atmosphere, followed by the deployment of parachutes and the firing of retrorockets, for a soft landing. The spacecraft.vill be protected. within a cluster of airbags. The chosen landing site is at the confluence of two large channels, Ares and Tiu Vallis, that drain from the uplands south of the Chryse Planitia basin. After landing, the deflated airbags will retract and the tetrahedral-shaped spacecraft will open to release its instruments, solar panels, and Sojourner. Surface operations are scheduled to last a minimum of 30 days, with a goal of 1 year. The lander, whose payload is only one-third as massive as its. Viking counterpart's, is equipped with a stereo camera.(equipped with 24 filters) and a meteorology station. In addition, Sojourner carries its own imaging system and an alpha-proton- $x$-ray spectrometer (APXS) for chemical analysis of rocks and soil.

\section{Assessment of Mars Pathfinder}

The science results will depend on what is visible at Pathfinder's landing site and what is accessible for analysis. The imaging is likely to show details that will help to elucidate erosion, transportation of rocky materials by.large floods, and surface modification by the wind. However, lack of descent imaging will hinder the analysis of these data, especially for determining the geologic context of the site and for providing a link to orbiter observations. The meteorology measurements :rill give an indication of year-to-year variability when compared with the Viking data, since the proposed touchdown is fairly close to the Viking 1 landing site. Potentially the most scientifically important result from Mars Pathfinder will be a better understanding of the martian highlands (see immediately below), whose nature is largely unknown.

The Ares and Tiu Vallis floods are likely to have deposited a mix of highland rocks at the landing site. Crater ages indicate that the floods occurred in the first half of Mars's history, after the end of heavy bombardment. Although their exact sources will not be known, the highland rocks are probably an aggregation of primordial crust (a product of global fractionation at the end of accretion), ancient volcanic rocks, ancient sediments, and 


\section{REFERENCES}

1. Space Studies Board, National Research Council. An Integrated Strategy for the Planetary Sciences: 1995-2010. National Acaderny Press. Washington, D.C., 1994

2. NASA. Marc Science Working Group, A Strategy for the Scientifc Exploration of Mars. PL D-8211. Jet Propulsion Laboratory. Pasadena. Calif.. February 1991.

3. Intemational Mars-Science Working Group, "An International Strategy for the Exwloration of Mirre" planotam and Snace Srionce in

$$
=
$$




\section{Overview of Mars Surveyor and Other Mars Missions}

In this chapter COMPLEX desciibes NASA's plans for the exploration of Mars by its own spacecraft and by U.S. participation in international missions. Throughout this description, COMPLEX points out how these

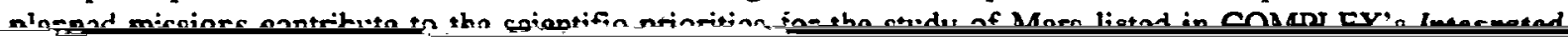
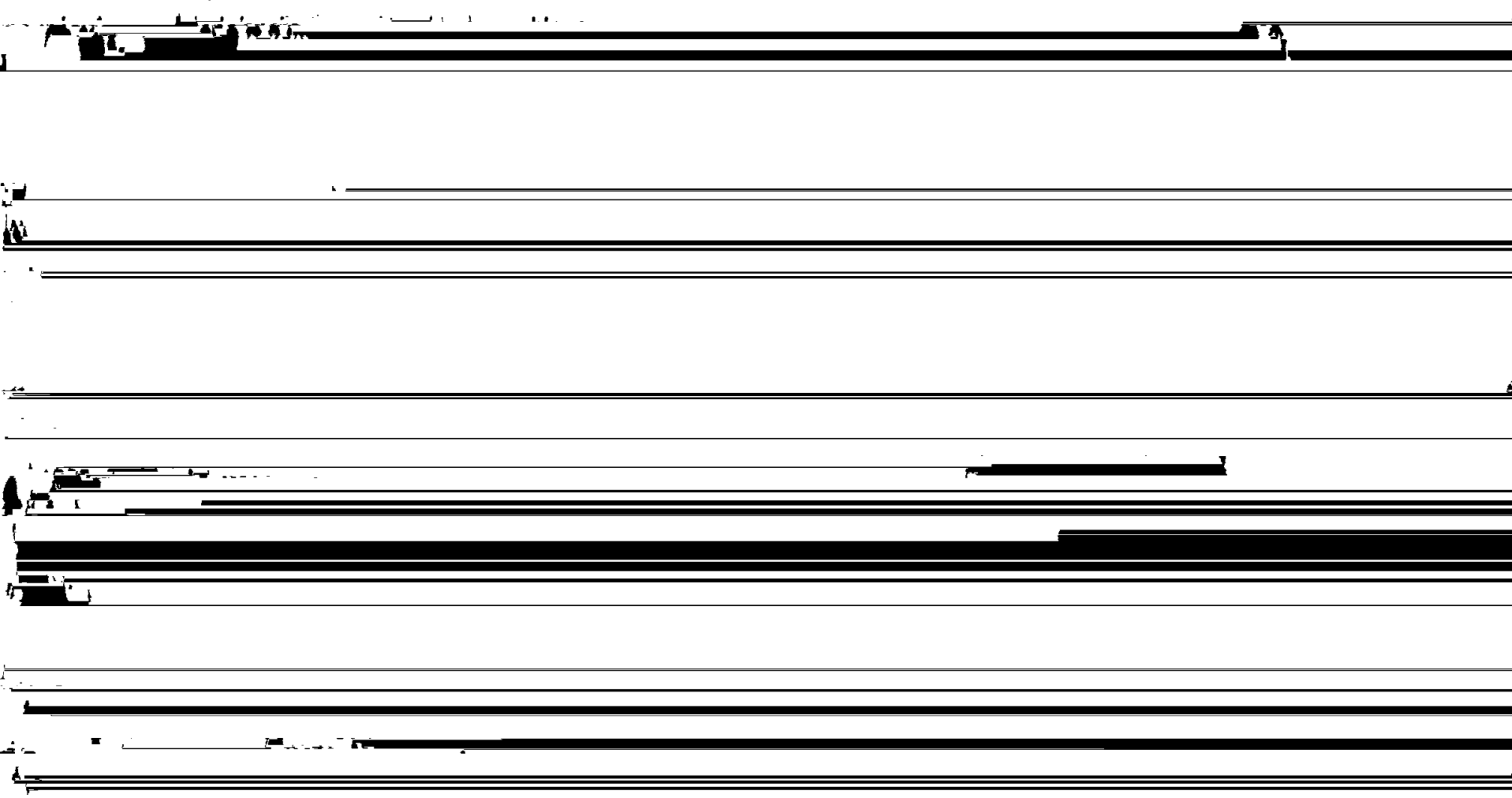

( 


\section{REFERENCES}

1. Space Studies Board, National Research Council. An Integrated Strategy for the Planetary Sciences: 1995-2010. National Acaderny Press. Washington, D.C., 1994

2. NASA. Marc Science Working Group, A Strategy for the Scientifc Exploration of Mars. PL D-8211. Jet Propulsion Laboratory. Pasadena. Calif.. February 1991.

3. Intemational Mars-Science Working Group, "An International Strategy for the Exwloration of Mirre" planotam and Snace Srionce in

$$
=
$$




\section{LAUNCH OPPORTUNITY}

Missions during the 2001 launch opportunity are currently undefined and will present a particular challenge because of the location of Mars along its elliptical orbit. As a result, atypically high energies are required for orbit insertion.

\section{Mars Surveyor 2001}

Although their payloads may be smaller than those dispatched to Mars in 1996 and 1998, a suitably modified Med-Lite booster will be able to transport an updated version of the Gamma-Ray Spectrometer (GRS), thereby completing the flight of all of the Mars Observer instruments. The second launch during the 2001 launch opportunity will likely be of a small lander, whose objectives are yet to be determined. Another possibility is a cooperative mission with another partner such as Russia. which has deferred the launching of a Marsokhod minirover (see Table 1 for specifications) and a balloon until at least this launch window.

\section{Preliminary Assessment of Mars Surveyor 2001 Orbiter. (with GRS)}

The flight of GRS to Mars in 2001, if feasible, would be a significant achievement. This instrument provides data that are essential to Mars Surveyor's goals of studying life, climate, resources, and water. Its prime function is to determine the chemical composition of the surface and investigate how that composition varies from place to place. The bulk chemistry of the crust will yield important constraints on how the crust, mantle, and core formed, while local and regional differences will give clues about a wide variety of fractionation mechanisms, such as hydrothermal alteration and evaporation of lakes.

The GRS is also the only Mars Observer experiment capable of directly observing water in the regolith and mapping its near-surface extent and temporal variations. Accordingly, data from this experiment will also substantially improve our understanding of the sources, sinks, and exchange precesses of water in today's climate. Because the GRS maps chemical variations across the surface, its data are essential for choosing the landing sites of future missions.

\section{LAUNCH OPPORTUNITY}

NASA currently has no defined mission plans for the 2003 launch opportunity. As part of its Horizon 2000 Plus strategic plan, ${ }^{7}$ the European Space Agency (ESA) is examining the feasibility of using its new Ar: ine V launch vehicle to transport three or four small landers and a communications relay orbiter to Mars in 2003 . The principal goal of this Intermarsnet mission is to establish a network of simultaneously operating seismology stations. ${ }^{8}$ Implementation of the mission is contingent on NASA's providing the landers. ESA is to contribute the communications orbiter and the launch vehicle. At the time of writing, the status of Intermarsnet is in considerable doibbt. Budgetary problems at ESA may force the postponement of the mission (to later than 2003) or lead to its outright nonselection. Moreover, the failure of Ariane $\mathrm{V}$ during its first test flight and the consequent loss of its payload, the high-priority Cluster mission, have thrown ESA planning into disarray. This launch window may be the best opportunity to deploy a global network of simple meteorology stations with concurrent orbital sounding because an orbiter is already included in the Intermarsnet program.

Preliminary assessments suggest that 15 to 20 microlanders could bc accommodated within the restrictions of a Med-Lite payload. It is not clear, however, whether development costs of both microlanders for the NASAonly mission and landers derived from the 1998 and 2001 designs for Intermarsnet can be accommodated within the cost constraints of the Mars Surveyor program. 


\section{LAUNCH OPPORTUNITY}

Sampie return has long been a major U.S. objective for Mars exploration. ${ }^{9}$ NASA has designated it as a goal for the 2005 launch opportunity. Sample return missions defined in the late-1980s called for multiple landers with masses of many thousands of kilograms and requiring billion-dollar budgets. ${ }^{10}$ However, despite large reductions over the last several years in the expected costs and launch masses required for sample retum, sample return could be very difficult under the present guidelines for the Mars Surveyor program (i.e., that spacecraft cost approximately $\$ 100$ million and have a mass of a few hundred kilograms or less). Nevertheless, sample retum's retention as a goal for a mission almost a decade hence emphasizes its.importance and the necessity of devising cheaper ways of accomplishing it.

If it turns out that indeed sample return cannot be accomplished within the Mars Surveyor program, then it will be appropriate to reconsider the importance of laboratory specimens for truly understanding Mars. If, as seems highly likely, sample return continues to be of paramount interest, the nation will need to study options for a larger program (e.g., $\$ 300$ million to $\$ 400$ million) that will return samples.

\section{REFERENCES}

1. Letter repon regarding an assessment of the impact on integrated science retum from the 1992 Mars Observer mission, from the Committee on Planetary and Lunar Exploration to Geoffrey A. Briggs (NASA), July 12. 1988.

2. Daniel J. McCleese. Mars Surveyor Program Scientist, presentation to COMPLEX, February 9, 1995.

3. Office of Space Science, NASA Headquarters Guidelınes: Mars Surveyor Program. NASA, Washington, D.C.. 1995.

4. Letter report regarding an assessment of the impact on integrated science retum from the 1992 Mars Observer mission, from the Committee on Planetary and Lunar Exploration to Geoffrey A. Briggs (NASA), July 12. 1988.

5. Space Studies Board, National Research Council, An Integrated Strategy for the Planetary Sciences: 1995-2010, National Academy of Sciences. Washington. D.C.. 1994. pp. 103-105 and 191-193.

6. Mars Aeronomy Observer Science Working Team. Mars Aeronomy Observer: Repon of the Science Working Team. NASA Technical .Memorandum 89202. Jet Propulsion Laboratory, Pasadena. Calif., October 1. 1986.

7. European Space Agency (ESA), Horizon 2000 Plus: European Space Science in the 21st Century. ESA SP-1180, ESTEC, Noordwijk. The Netherlands, November 1994.

8. European Space Agency (ESA), Intermarsnet: Report of Phase-A Study, ESA Publication D/SCI(96)2. ESA. Paris. April 1996.

9. Space Science Board, National Research Council. Strategy for Exploration of the Inner Planets: 1977-1987, National Academy of Sciences, Washington, D.C.. 1978.

10. Sec. for example, Science Applications Intemational Corporation (SAIC), Planetary Mission Performance Handbook, Volume IV: Mission Descriptions. SAIC-86/1853, SAIC, Schamburg, II1., August 1986, pp. 101-116. 


\section{Key Issues for NASA's Mars Exploration Program}

In the course of COMPLEX's examination of NASA's program for the exploration of Mars, several issues arose. They are as follows:

- The completion of global mapping,

- Enhancing mobility,

- The adaptability of the program,

- The role of international partners,

- The development of instrumentation, and

- Sample retum.

These issues are discussed in the following sections.

\section{COMPLETE GLOBAL MAPPING}

Various science advisory group,s are consistent in emphasizing the need to complete the global mapping originally planned for Mars Observer. Such mapping will place our current martian data in a global context and should lead to major revisions in our understanding of how the planet has evolved. It will accordingly provide a general framework for planning future exploration. A prerequisite for future studies of Mars is the reflight of those Mars Observer instruments not scheduled to be carried by Mars. Global Surveyor, at the earliest possible date (i.e., PMIRR in 1998 and GRS in 2001).

Completion of the objectives of Mars Observer does not necessarily imply that no more remote sensing will be necessary. Discoveries by the program in the next 5 years may indicate the need for further orbital observations at a later time. At present we have limited knowledge of the chemical, mineralogic, and lithologic variety present at the martian surface, the scales over which such differences occur, and the remote-sensing techniques best suited for their detection. Hydrothermal deposits, for example, are of special interest for exobiology' yet may be so localized as to not be detectable unambiguously by the $3-\mathrm{km}$ resolution of the TES instrument $t^{2}$ be flown in 1996. Consequently, high-resolution remote sensing data for sclected areas and ground-truth measurements will be important for understanding the global data sets. The medium-range strat- 
egy should therefore be sufficiently flexible that it can adapt to new knowledge, and be amenable, for example, to schedule additional remote-sensing missions should they prove necessary.

\section{ENHANCE MOBILITY -}

To address the main scientific goals of the Mars Surveyor program, mobility is necessary at the landing sites. While three components of the planet are available for measurement (the atmosphere, the loose material at the surface, and the solid planet), just the first two are expected to be accessible at most sites. Thus only some components of Mars can be effectively characterized without significant mobility. The atmosphere and soils are expected to furnish important information on the climatic history of the planet. The dynamics of th ;resent atmosphere supplies clues about the behavior of past atmospheres, while the atmosphere's chemistry provides information on its original composition, losses from the upper atmosphere, and interactions with the surface. Similarly, the soil may suggest weathering conditions in the past and indicate how near-surface volatiles migrate. Unfortunately, the atmosphere and the soil have serious drawbacks in terms of contributing to understanding of biology and long-term climate. Since the records contained in the atmosphere and soil are cumulative, with each sample representing a single point on an evolutionary path, many paths could lead to today's conditions. Thus any reconstruction of planetary history from such records is ambiguous.

The rock record, in contrast, displays discrete events whose time sequence can be reconstructed. Each rock unit chronicles a specific occurrence such as a volcanic eruption, a flood, a lake's evaporation, or a large impact; from the ordering of the units the events can be placed in a time sequence. A rock's lithology, mineralogy, chemistry, and other characteristics give evidence of the prevailing conditions under which the rock was deposited. Rocks are commonly preserved by deposition and burial. Through this process, past atmospheres, organics, or hydrothermal mineral assemblages may be insulated from subsequent surface conditions, thus preserving them so.that they may be available for scrutiny.

The solid rock record has the highest potential, therefore, for providing unequivocal evidence for past life: the most favored targets are lacustrine sediments, ancient hydrothermal deposits, and evaporites. Rocks can also indicate past climates through fluvial deposits, trapped atmospheres, and weathering horizons. Finally, the rock record supplies the best documentation for how the solid planet has evolved. In order to address the scientific goals of the Mars Surveyor program, therefore, the rock record must be accessed and, to accomplish that, mobility is essential. Unlike the atmosphere and soil, the rock record is very heterogeneous and scattered. The rock types of greatest interest for studies of water, climate, and life are likely to be present at only a few locations.

The remote-sensing data will suggest-where best to go, but landers will need to carry components that are able to move about and search areas of interest, rather than be restricted to examining whatever happens to be close to the lander upon its arrival. In addition, some sites of high interest for the study of environments conducive to life, such as lacustrine/fluvial sediments and mineralized zones around hydrothermal vents, are very localized and virtually impossible to target with the existing navigational capabilities. Thus, in order to have a reasonable chance of successfully addressing questions of climatological and biological interest, the landers need to be equipped with rovers that move about, explore, and sample candidate sites.

The distances required to move cannot be stated precisely without more information on Mars, but in view of the heterogeneity of the martian surface, the landing errors anticipated, and the prospects for future rover development, mobilities of tens of kilometers appear necessary (see Table 1 for the specifications of Sojoumer, Marsokhod, and a strawman advanced rover). Such rovers must carry appropriate instruments since the purpose of mobility is to make measurements at different places away from the immediate landing site. Development of a roving capability is, therefore, intimately connected with the need for miniaturization of scientific instruments, discussed below. These mobility requirements may be mitigated partly by improving the accuracy of landing; nevertheless, ever, with a capability to do a pinpoint landing, some mobility will be essential to sample a variety of sites.

A major issue for the Mars Surveyor program is that the small landers planned for the next decade are likely to have very limited mobility. The 1998 lander, for example, has a total payload mass of $22 \mathrm{~kg}$. Owing to the 
need to accommodate science instruments and devices for the manipulation of samples, little mass is left to enable significant movement around or from the landing site. COMPLEX considers this inadequate to meet the stated objective of accessing the information contained in the martian rock record in a variety of terrains. ${ }^{2}$

Because of the essential information provided by detailed analyses of rock fragments at different sites, NASA must aggressively pursue ways to enhance the mobility of landers and other vehicles in order to allow measurements to be made on a variety of rocks and terrains. This development can evolve as lander designs and technologies advance. International participation-for example through the use of Russian launch vehicles and Marsokhod minirovers, and French balloons-would also improve the opportunities for mobility on, or close to, the martian surface.

\section{ASSURE AN ADAPTABLE PROGRAM}

At present the Mars Surveyor program is highly structured, with guidelines calling for pairs of launches at each launch opportunity, and for all U.S. launches to be on Med-Lite vehicles. Because of launch energy constraints, any lander planned for the 2001 launch opportunity is likely to be a downscaled version of the 1998 lander, and the 2003 landers could, perhaps, be even smaller. The main opportunities for adaptation to scientific findings and new concepts are in the choice of landing sices and, possibly, improved instruments. Nevertheless. within the guidelines.various mission types can be accomplished, including small landers as planned, balloon missions, and networks of miniature meteorology stations. NASA's experience with Discovery proposals demonstrated that the space science and engineering communities are extremely resourceful in designing a wide variety of highly innovative and cost-competitive mission concapts. COMPLEX has stressed the virtues of flexibility in small mission programs. ${ }^{3}$ Given the relatively long life of the Mars Surveyor program, advances in both technology and our knowledge of the martian surface and atmosphere should permit revolutionary changes in how program goals might be best achieved. In view of today's incomplete understanding of Mars, plus the complex and dynamic nature of the planet, it is highly desirable to maintain maximum flexibility in the program to allow for adaptation to any new discoveries and unpredicted opportunities. The program should be sufficiently flexible to incorporate such changes, in addition to the incremental improvements envisaged for the small.landers as.they evolve from 1998 through 2003.

COMPLEX is concerned that strict adherence to the guidelines of multiple launches at all opportunities may be too constraining. The planetary science community accepts the necessity to stay within the mandated cost cap, but also recognizes that different strategies may be followed within the cost constraint. The current plan of having multiple flights during each launch window has the advantage of distributing risk, thereby reducing the chance of complete failure at any launch opportunity. However, in some circumstances, this benefit may be offset by the scientific advantages of placing a single larger capability at Mars, as mentioned in the preceding section, where mobility and scientific capability are both seen to be required for effective landers. Under the present guidelines, it may not be possible to place a long-range, well-instrumented rover on the surface of Mars, particularly one equipped with, for example, sophisticated exobiologic instruments. Sample retum is another example: despite major advances in determining how this long-time goal of Mars exploration might be accomplished at modest cost, sample. return still appears to need larger payloads at Mars than can be delivered currently with Med-Lite launch vehicles.

How can the Mars Surveyor program retain the adaptability to take advantage of scientific and technological opportunities as they become available? Ideally, mission profiles should not be fixed earlier than two launch. opportunities prior so that advisory groups can monitor progress and propose necessary program changes. NASA should investigate the realism of this suggestion and also study the use of different permutations in the number of launches and launch vehicles.

\section{ENGAGE INTERNATIONAL PARTNERS}

At the present time NASA has three potential international partners for joint missions to Mars: Japan. Russia, and the European Space Agency. In addition, many other partners are available for cooperation at lesser levels, 
such as provision of science instruments. Russia is supplying some components of PMIRR to be flown in 1998 and a lidar.system for the 1998 polar land... NASA is building the neutral mass spectrometer for the Japanese mission Planet-B to be flown in 1998. Talks are under way concerning the possibility of a joint U.S.-Russian mission that might involve the use of a Russian launch vehicle and a Marsokhod minirover. ESA and NASA conducted a joint study of the Intermarsnet mission, for which NASA would supply three or four small landers whose data would be relayed to Earth via an ESA orbiter. These landers would form a small seismology and meteorology network, as well as make geochemical measurements. - The meteorology network could be supplemented by a U.S.-only launch of very small meteorology landers.

These cooperative missions provide an important means for substantially improving the overall science retum of the Mars Surveyor program and, more importantly, for filling in important scientific gaps (e.g., global seismology and aeronomy) in NASA's program. COMPLEX commends NASA for aggressively pursuing these opportunities and encourages additional efforts to engage international partners, both at the missions level and in mutual provision of other capabilities such as relay l.nks and scierice instruments.

\section{DEVELOP MICROINSTRUMENTS}

The success of the Mars Surveyor program beyond completion of the Mars Observer goals will depend largely on the capability of the landers deployed on the martian surface. In this regard, the program is seriously constrained by the performance of the proposed Med-Lite vehicle. Expectations are that the useful mass of NASA's Mars landers will decline substantially between.1996 and 2003. It is possible, however, that reductions in spacecraft mass may be counterbalanced by developments outside the. Mars Surveyor program. In addition to Mars Surveyor 1998's pair of microlanders, the New Millennium program will, ${ }^{4}$ for example, develop and test new materials, avionics, and spacecraft designs.that could lead to significantly smaller spacecraft. Nevertheless, the ability to reduce the mass needed to achieve a successful landing on Mars will have limited value to the Mars Surveyor program unless accompanied by a parallel development of microinstruments, that. is, instruments significantly smaller than those currently available. It serves little purpose to deliver small spacecraft to the surface of Mars unless they have useful analytical capabilities.

Sophisticated microinstruments will be increasingly required as the Mars Surveyor program matures. Not only will lander masses likely decline, but the relatively easy, exploratory observations also will have been performed. Later landers are likely to be smaller and yet be required to conduct more sophisticated observations. As emphasized in the section above on mobility, the rock record must be examined to enable progress toward understanding the climatic and exobiologic history of the planet, and this effort will require significant. mobility. In addition, to do anything other than remote sensing, eventually we will need devices to acquire and prepare samples. All these capabilities must be included within the payload allocation.

Landers will need to measure the mineralogy. of primary silicates and low-temperature volatiles, and isotopic compositions of atmospheric gases as well as of stable and radiogenic species in secondary minerals such as clays and carbonates to detect and characterize organic matter; and to determine various trace elements. It will also be necessary to examine microscopically both in situ and prepared samples, and to carty out various kinds of mineralogical and chemical analyses under the microscope. Many analytical techniques require sample preparation. The development of sample-acquisition and sample-preparation techniques must therefore be a part of NASA's instrumentation program.

Funding within the Mars Surveyor program itself is too limited to foster significant advances in instrument designs. Although NASA does have a relevant program for this, the Planetary Instrument Definition and Development Program (PIDDP), it is relatively modest and concentrates on instruments that are likely to be chosen for flight in the near term. Previous reports by COMPLEX ${ }^{5}$ and other. National Research Council committees $^{6}$ have recommended that NASA devote more attention to the provision of instruments for smallspacecraft missions. The long-term development of microinstrumentation could be a part of, or independent of, the New Millennium program. 


\section{MAINTAIN GOAL OF SAMPLE RETLRY}

Sample return has long been a goal of Mars exploration. ${ }^{7}$ Many critical measurements are too complicated and interactive to perform remotely on a distant planet in the foreseeable future. Determinations of absolute ages, for example, strain the capabilities of terrestrial laboratories yet are essential for understanding how a planet has evolved. Only very recently have techniques been developed for determination of $\mathrm{D} / \mathrm{H}$ and oxygen isotopes on different temperature extracts from Shergotty-Nakhla-Chassigny meteorites that are believed to be from Mars; these measurements have proved invaluable in improving our understanding of the evolution of water on the planet. Because trace elements are so strongly fractionated in geologic processes, they are excellent markers of past processes. Yet many of the determinations are very difficult measurements to make even in sophisticated terrestrial laboratories. Microscopic techniques for detection of Archean life on Earth have been developed only in the last two decades and would be extraordinarily difficult to employ remotely at Mars. The challenge presented in conducting these cr.ically needed analyses on a remote planet is a primary reason for requiring retumed samples. Furthermore, the diverse nature of Mars argues that samples will need to be rutumed from many sites, presumably necessitating several flights or long-range rovers before a fairly complete inventory will have been taken.

Sample return can also be justified for operational reasons. Spacecraft to Mars will be able to carry only a limited number of instruments and do a restricted set of measurements. It is not possible, a priori, to identify the most critical measurements to make. Having samples on Earth enables a wide range of measurements to be made and permits adjustment of the measurement strategy in response to previous.analytical results. New techniques can be developed in response to results obtained from the samples themselves.

Experience with the Moon emphasizes the enormous value of returned samples when placed in the context of global data. The lunar sample data provide the basis for almost all our ideas about how the Moon evolved. With lunar samples in hand, the analytical approach became wide-ranging and flexible, such that the emphasis could shift as the meaning of each set of results became clear. These advantages should be even greater on Mars, given the more complex geology and the possibility of past life.

The above ideas are not new. The Committee on Human. Exploration of the Space Studies Board recently stated that "to take best advantage of human capabilities in scientific exploration, it will be desirable, some argue essential, to retum reconnaissance samples from Mars prior to human exploration." The reasons for this are those above-an improved knowledge of martian processes and history, which "will permit a more informed choice of the landing sites . . . and the types of investigations [to conduct]" planetary quarantine and soil toxicity.

The projected costs of sample return and the launch masses required have both declined dramatically in the last decade. Despite this, it is still not clear whether sample return can be achievcu within the mass and cost constraints placed on the Mars Surveyor program. This.is especially true if-rock samples, as argued above, are to be returned. COMPLEX is encouraged that NASA continues to retain sample return as a goal and that the agency has recently indicated that the number of launches and launch vehicle constraints originally placed on the Mars Surveyor program may be relaxed provided that there are compelling reasons. COMPLEX reemphasizes the importance of returning samples of martian soil, atmosphere, and, especially, rocks and commends NASA for retaining sample retum as part of the Mars Surveyor program. Taking this option, however, places the onus on NASA to explore ways that will allow samples (including rocks) to be returned within the constraints of the Mars Surveyor program. If studies show that this is not possible, then Mars sample return will need to be considered as a stand-alone, high-priority scientific program that must compete against NASA's other scientific goals.

\section{REFERENCES}

1. Exobiology Program Office, Exobiological Strategy for Mars Exploration. NASA. Washington. D.C.. 1995. Space Studies Board. National Research Council, 1990 Update to Strategy for Exploration of the Inner Planets, Sational Academ: Press. Viashington. D.C.. 1990, p. 22. 
3. Space Studies Board, National Research Council. The Role of Small Missions in Planetary and Lunar Exploration. National Academy Press, Washington, D.C., 1995.

4. E. Kane Casani, Exploration for the 21st Censun: The New Millennium. Jet Propulsion Laboratory, Pasadena, Calif., January 1995.

5. See. for example, Space Studies Board. National Research Council, The Role of Small Missions in Planetany and Lunar Exploration. National Academy Press, Washington, D.C., 1995, pp. 20 and 28.

6. See. for example. Space Studies Board, National Research Council, Managing the Space Sciences, National Academy Press, Washington, D.C., 1995, pp. 3, 65-66, and 75.

7. See, for example, Space Science Board, National Research Council, Strategy for Exploration of the Inner Planets: 1977-1987, National Academy of Sciences, Washington, D.C., 1978, and Space Studies Board, National Research Council, An Integrated Strategy for the Planetan Sciences: 1995-2010, National Academy Press, Washington, D.C., 1994.

8. Space Studies Board, National Research Council, Scientific Opportunities in the Human Exploration of Space. National Academy Press, Washington, D.C., 1994, p. 13.

9. Space Studies Board, National Research Council. Scientific Opportunities in the Human Exploration of Space, National Academy Press, Washington. D.C.. 1994, D.13. 


\section{Assessment of the Scientific Potential of NASA's Mars Exploration Program}

According to its current formulation, NASA's Mars program has the potential to achieve the following over the next decade:

1. Accomplish the goals of Mars Observer, although stretched over several launches, and so provide the basic global data needed to guide future exploration;

2. Add to our knowledge of the regolith's chemistry and mineralogy, and the isotopic composition of the atmosphere, thereby leading to improved information about past climates;

3. Achieve understanding of the exchange of volatiles at high latitudes;

4. Better.characterize the dynamics of the atmosphere; and

5. Ascertain the geomorphologic characteristics of the surface and the nature of the local rock record at several landing sites.

Should ESA's Intermarsnet mission progress with NASA's participation, the program will also:

6. Determine the internal structure of the planet and the present level of seismic activity.

This is a vigorous and challenging program in an era of reduced science funding. The three themes of the Mars Surveyor program (life, climate, and resources), plus the unifying topic of water, are responsive to the priorities given in previous science plans, such as the Integrated Strategy (as long as NASA's current interpretation of "resources" as covering the study of martian geology, geophysics, and geochemistry continues to hold), and capture the overall objectives of the scientific community.

COMPLEX is, however, concerned about several engineering and technical aspects and about NASA's ability to carry them out within a relatively modest budget. These include:

- The number.of launches that must be accomplished;

- The variety of new spacecraft that must be developed; and

- The technological challenges set by the restricted size of the spacecraft and their payloads.

Nevertheless, COMPLEX believes that NASA's Mars program is aggressive and scientifically exciting. It 
holds enormous promise for advancing our understanding of this, the most Earthlike of the planets. Although it does not meet ali scientific requirements (e.g., in aeronomy, internal structure, and seismic activity, or with respect to a sophisticated exploration for extant or extinct life), its scientific potential is great and will be broadly consistent with a significant subset of the scientific priorities outlined in the Integrated Strategy provided that:

- The program of global mapping planned to begin with Mars Giobal Surveyor in 1996 is completed by' flying the Pressure Modulator Infrared Radiometer in 1998 and the Gamma-Ray Spectrometer in 2001;

- The mobility of landers and other vehicles is enhanced beyond that exemplified by Mars Pathfinder's rover so as to allow measurements to be made on a wide variety of rocks and terrains;

- The Mars Surveyor program is kept flexible so that it can respond to scientific and technological opportunities and can encompass a broad range of mission modes;

- International partners continue to be involved in order to supplement U.S. capabilities and leverage U.S. resources committed to the program;

- An aggressive program for development of miniaturized instruments is initiated; and

- The goal of returning samples of martian soil, atmosphere, and, most importantly, rocks remains a central element of NASA's planning. 